\title{
Perforated $\mathrm{ZnO}$ nanoflakes as a new feature of $\mathrm{ZnO}$ achieved by the hydrothermal-assisted sol-gel technique
}

\author{
Zahra Khaghanpour ${ }^{1} \cdot$ Sanaz Naghibi $^{1}$ (B)
}

Received: 21 November 2016/Accepted: 4 January 2017/Published online: 23 January 2017

(C) The Author(s) 2017. This article is published with open access at Springerlink.com

\begin{abstract}
The perforated $\mathrm{ZnO}$ nanoflakes with high degree of crystallinity and uniformity were synthesized via the hydrothermal-assisted sol-gel technique without any template. $\mathrm{ZnCl}_{2}$ was used as a $\mathrm{Zn}$-containing precursor, causing the oriented growth of particles. The observation of a hole on the facet of the as-synthesized particles was discussed in this work. XRD, TEM, and DRS were used to investigate the prepared powder and a simple mechanism was suggested to explain the hole formation on the surface of nanoflakes. As a result, the synthesized powder included pure $\mathrm{ZnO}$ with direct band gap energy of $3.24 \mathrm{eV}$. The range of particle size was within $1 \mu \mathrm{m}$ in diameter and $<50 \mathrm{~nm}$ in thickness. A circle hole with $300-500 \mathrm{~nm}$ in diameter was observed on the facet of the as-synthesized particles.
\end{abstract}

Keywords $\mathrm{ZnO}$ nanoflakes - Perforated flake .

Hydrothermal $\cdot \mathrm{ZnCl}_{2} \cdot \mathrm{TEM}$

\section{Introduction}

The hollow and perforated particles have recently attracted several scientists. For this reason, several methods and techniques have been presented and the improvement of the properties and the characteristics of the particles have been identified. Due to the unique morphology, the perforated particles have found specific applications in bioscience, energy storage, conversion, and adsorbents [1-4].

Sanaz Naghibi

naghibi@iaush.ac.ir

1 Department of Materials Engineering, Shahreza Branch, Islamic Azad University, Pasdaran St., PO Box 86145-311, Shahreza, Isfahan Province, Iran
$\mathrm{ZnO}$ as a well-known ceramic material has become an interesting topic for several researches, and numerous preparation routs [5, 6], morphologies [7-10], and characteristics $[11,12]$ have been reported. The crystal structure of $\mathrm{ZnO}$ wurtzite is hexagonal. $\mathrm{Zn}$ and $\mathrm{O}$ atoms fill the crystallographic planes and form their unit cell. The anisotropic growth of $\mathrm{ZnO}$ crystallites is related to this structure, forming a large variety of features [13]. Morphology control of $\mathrm{ZnO}$ particles is an important parameter determining structure characteristics. Varieties of morphologies of $\mathrm{ZnO}$ particles have been synthesized with rodlike, hexagonal pyramid-like, truncated hexagonal conical, cauliflower-like, tubular, hourglass-like, flake-like, aggregate, and spherical shapes [7-10].

Nguyen et al. have been developed a template-based method for the preparation of hollow particles. In this approach, the $\mathrm{ZnO}$ hollow particles were synthesized via facilitating nucleation of $\mathrm{ZnO}$ crystallites under ultrasonic treatment. This process caused rising pressure and temperature at the interface between the cavitation bubbles (generated by ultrasonic vibrations) and the precursor solution. The solution temperature was measured up to $150{ }^{\circ} \mathrm{C}$. In such circumstances, sol-gel stages (i.e., hydrolysis, pyrolysis, and condensation) occurred around the bubbles. In other word, the cavitation bubbles played important role in this process by providing uniform templates for the formation of hollow $\mathrm{ZnO}$ structure [14].

Zhang et al. have been synthesized $\mathrm{ZnO}$ hollow spheres by utilizing carbon microspheres as templates. In this process, $\mathrm{Zn}$ precursor was dissolved in dimethylformamide (DMF). Carbon microspheres as the sacrificial template and water as the hydrolysis agent were added to the solution. After a while, a puce precipitate was obtained. $\mathrm{ZnO}$ hollow spheres were obtained by heat treating the precipitated powder at $450{ }^{\circ} \mathrm{C}$ [15]. 
Jin et al. have been prepared hollow $\mathrm{ZnO}$ microsphere by a chemical method using polymethyl methacrylate (PMMA) as template. For this reason, PMMA powder, distilled water, and ammonia were mixed. After a while, $\mathrm{Zn}$ precursor was added to the solution, and then, the $\mathrm{pH}$ was adjusted to 8.5 using $\mathrm{NaOH}$. The obtained precipitated powder was calcined at $350{ }^{\circ} \mathrm{C}$. The synthesized microspheres were comprised of several layers of $\mathrm{ZnO}$ particles with hollow diameter of $\sim 10 \mu \mathrm{m}$. [16].

Zhu et al. have used electrospinning and subsequent heat treatment to achieve hollow $\mathrm{ZnO}$ nanospheres. For this reason, $\mathrm{Zn}$ precursor was dissolved in distilled water and then added to the solution of polyvinyl pyrrolidone and ethanol. The obtained solution was applied by electrospinning process. The hollow $\mathrm{ZnO}$ nanospheres with an average diameter of $\sim 250 \mathrm{~nm}$ were formed [17].

As can be seen, most of the researches have been focusing on using sacrificial template to achieve the hollow structures.

This paper focused on introducing a new morphology of $\mathrm{ZnO}$ particles. The hydrothermal-assisted sol-gel method was applied and zinc chloride was used as the $\mathrm{Zn}$ precursor. As a result, $2 \mathrm{D} \mathrm{ZnO}$ hexagonal single crystals with dimension of $>1 \mu \mathrm{m}$ were obtained. Interestingly, there are micron-sized hole on the as-synthesized $\mathrm{ZnO}$ flaks. It should be mentioned that this procedure is a template-less method. This phenomenon and its plausible mechanism will be explained.

\section{Materials and methods}

In this work, zinc chloride $\left(\mathrm{ZnCl}_{2}, 99.8 \%\right.$, Merck, Germany), triethylamine (TEA, >99\%, Merck), and distilled water were used as the precursor, $\mathrm{pH}$ adjusting reagent, and solvent, respectively. An adequate amount of $\mathrm{ZnCl}_{2}$ was added to water to achieve a clear solution with the concentration of $5 \mathrm{~g} / \mathrm{L}$. Then, TEA was added to the stirring solution to make the $\mathrm{pH}$ reach 9 . The precipitation occurred after $24 \mathrm{~h}$ and a white suspension achieved. This suspension was then treated by an autoclave for $2 \mathrm{~h}$ at $200{ }^{\circ} \mathrm{C}$, and dried in an oven to obtain a white powder.

This powder sample was characterized using X-ray diffraction analysis, XRD (by a PANalytical's diffractometers, X'Pert Pro., The Netherlands), transmission electron microscopy, TEM (by a LEO equipment, Japan), as well as diffuse reflection spectroscopy, DRS (by a UVvisible scanning spectrophotometer, JASCO, Japan).

Based on the DRS results, the direct bandgap energy $\left(E_{\mathrm{g}}\right)$ was measured in accordance with the Tauc method explained elsewhere [18], via plotting $(\alpha h v)^{2}$ versus $h v$, where $\alpha$ and $h v$ are the photon energy and the absorption coefficient, respectively. The linear part of the curve extrapolated to $h v$ axis to achieve $E_{\mathrm{g}}$ value.
The photocatalytic behaviors of the synthesized sample as well as $\mathrm{TiO}_{2}-\mathrm{P} 25$ were investigated via measuring the degradation of methylene blue as described previously [19]. For this reason, $100 \mathrm{mg}$ of the powder samples were added to the methylene blue solution $(30 \mathrm{mg} / \mathrm{L})$, continuously stirred. The obtained suspensions were irradiated under UV lamp. The decomposition of methylene blue versus irradiation time was recorded by a UV-visible spectrophotometer. For this purpose, variation of the concentration, which is expressed as $\ln C_{0} / C$ (where $C_{0}$ refers to the initial concentration of methylene blue solution and $C$ depicts the concentration of methylene blue after UV irradiation), was plotted versus time of UV exposure (30, 60, 90, and $120 \mathrm{~min}$ ).

$\mathrm{TiO}_{2}-\mathrm{P} 25$ (Degussa, Germany) is one of the well-known commercial semiconductors. Expression characteristics of this powder along with the obtained results (about the assynthesized $\mathrm{ZnO}$ sample) could be useful for readers to give more detail on the interpretation of the characterizations.

\section{Results and discussion}

Figure 1 shows the XRD pattern of the sample, which can be attributed to the wurtzite [JCPDS: 75-576] with a space group of $\mathrm{Pb}_{3} m c$ and hexagonal crystal system without any

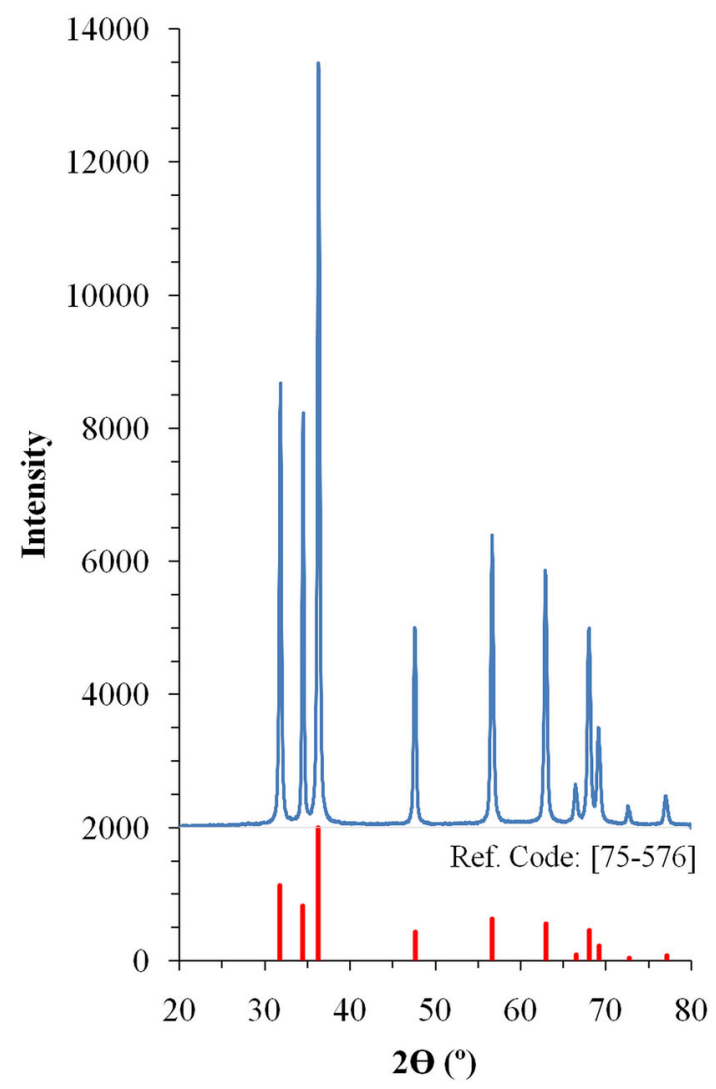

Fig. 1 XRD pattern of the as-synthesized powder along with the peaks of $\mathrm{ZnO}$ [JCPDS: 75-576] 
Table 1 Experimentally acquired peaks position and intensity along with the standard parameters of ZnO [JCPDS: 75-576]

\begin{tabular}{|c|c|c|c|c|c|c|c|c|c|}
\hline $\begin{array}{l}\text { Peak } \\
\text { no. }\end{array}$ & $\begin{array}{l}\text { Observed } \\
\text { position } \\
{\left[{ }^{\circ} 2 \Theta\right]}\end{array}$ & $\begin{array}{l}\text { Standard } \\
\text { position } \\
{\left[{ }^{\circ} 2 \Theta\right]}\end{array}$ & $\begin{array}{l}\text { Observed } \\
\text { intensity [cts, } \\
(\% *)]\end{array}$ & $\begin{array}{l}\text { Standard } \\
\text { intensity } \\
\text { [cts] }\end{array}$ & $\begin{array}{l}\text { Intensity } \\
\text { changes** } \\
{[\%]}\end{array}$ & $\begin{array}{l}\text { Observed } \\
\text { d-spacing } \\
{[\AA]}\end{array}$ & $\begin{array}{l}\text { Standard } \\
\text { d-spacing } \\
{[\AA]}\end{array}$ & $\begin{array}{l}\mathrm{d} \text {-spacing } \\
\text { changes*** } \\
{[\%]}\end{array}$ & $\begin{array}{l}\text { Miller } \\
\text { index }\end{array}$ \\
\hline 1 & 31.88 & 31.840 & 6395 (57) & 56.1 & +2 & $2.80,635$ & $2.80,826$ & -0.07 & 100 \\
\hline 2 & 34.53 & 34.503 & $5818(52)$ & 41.2 & +26 & $2.59,717$ & $2.59,740$ & -0.01 & 002 \\
\hline 3 & 36.37 & 36.337 & $11,133(100)$ & 99.9 & 0 & $2.46,968$ & $2.47,039$ & -0.03 & 101 \\
\hline 4 & 47.65 & 47.653 & $2861(26)$ & 21.5 & +21 & 1.9085 & $1.90,683$ & 0.09 & 102 \\
\hline 5 & 56.70 & 56.731 & $4192(38)$ & 30.9 & +23 & $1.62,345$ & $1.62,135$ & 0.13 & 110 \\
\hline 6 & 62.89 & 63.016 & $3492(31)$ & 27.2 & +14 & $1.47,638$ & $1.47,393$ & 0.17 & 103 \\
\hline 7 & 66.46 & 66.541 & $506(5)$ & 41.0 & -88 & $1.40,562$ & $1.40,413$ & 0.11 & 200 \\
\hline 8 & 67.98 & 68.120 & $2734(25)$ & 22.7 & +10 & $1.37,779$ & $1.37,538$ & 0.18 & 112 \\
\hline 9 & 69.20 & 69.261 & $1318(12)$ & 11.2 & +7 & $1.35,648$ & $1.35,549$ & 0.07 & 201 \\
\hline 10 & 72.59 & 72.759 & $258(2)$ & 18.0 & -89 & $1.30,123$ & $1.29,870$ & 0.19 & 004 \\
\hline 11 & 76.99 & 77.162 & 402 (4) & 35.0 & -89 & $1.23,751$ & $1.23,520$ & 0.19 & 202 \\
\hline
\end{tabular}

* The observed height $=($ peaks height/11,133 $) \times 100$; These values can be compared to the standard intensities

$* *$ Intensity changes $=[($ Observed Intensity-Standard Intensity $) /$ Standard Intensity $] \times 100$

$* * * d$-spacing changes $=[($ Observed d-spacing-Standard d-spacing $) /$ Standard d-spacing $] \times 100$

impurity. Table 1 presents all the experimentally acquired peaks position and intensity along with the standard parameters of this phase. The comparison between the intensity and d-spacing values of the standard $\mathrm{ZnO}$ as well as the observed pattern indicated that the as-synthesized particles may not be formed in regular shape. The orientated growth may occur in this process. By considering the intensity of the highest observed peak at $2 \Theta=36.37^{\circ}$ as $100 \%$, the relative intensities of the other peaks show that there are changes in some of the diffraction angles, such as $34.53^{\circ}, 56.70^{\circ}, 66.46^{\circ}, 72.59^{\circ}$, and $76.99^{\circ}$. On the other hand, the interplanar spacing values show changes compared to the standard values in the orientation along $<10 \overline{1} 3>,<11 \overline{2} 2>,<0004>$, and $<20 \overline{2} 2>$ directions. To evaluate this assertion, TEM could be useful equipment.

Figure 2 shows the TEM image of the as-synthesized powder. The hexagonal flake-like particles are observed with approximately $\emptyset=1 \mu \mathrm{m}$ and oriented in $<0001>$ direction [20]. This feature is due to the inherent structure of wurtzite. In addition, the thickness of the particles was $<50 \mathrm{~nm}$; therefore, these particles could be considered nanoflakes, which are similar to the other researchers' results $[9,20]$. This irregularity is related to the crystal growth along $c$ orientation. The $\mathrm{ZnO}$ crystallites are known as polar molecules, so that their polar faces are capable to absorb ions from the solution, in contrary ion adsorption along $c$ axis are restricted, and then, the growth along this axis declines. This is the reason of the flaky particles formation. Since TEA acts as a catalyst in this system [21], $\mathrm{ZnCl}_{2}$ ionizes into $\mathrm{Zn}^{2+}$ and $\mathrm{Cl}^{-}$. The $\mathrm{Zn}^{2+}$ participates in the crystallization

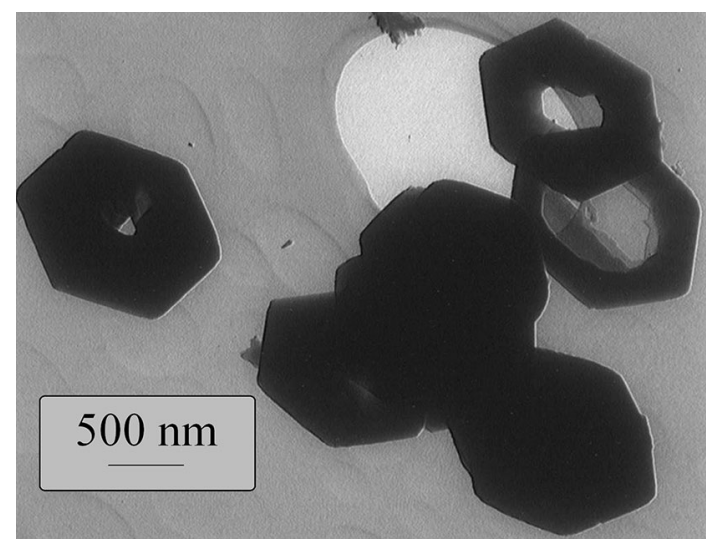

Fig. 2 TEM image of the as-synthesized powder

reactions, whereas $\mathrm{Cl}^{-}$ions determine the final feature of the particles. These ions adhere to the (0001) facet of the crystallites and hinder the proximity of $\mathrm{Zn}^{2+}$ and the crystallites surface [22].

The motivation for this work refers to the existence of a unique hole on the $\mathrm{ZnO}$ nanoflakes. This phenomenon has not been reported before, and this paper attempts to propose an impressive mechanism to investigate the preparation of perforated particles.

Figure 3 shows the schematic illustration of the suggested mechanism. In the early stages of the homogeneous nucleation, $\mathrm{Zn}(\mathrm{OH})_{2}$ molecules have an important role. Increasing time and temperature of the hydrothermal vessel causes to provide the nucleation condition. When the initial $\mathrm{ZnO}$ crystallites appear in the solution (Fig. 3I), $\mathrm{Zn}^{2+}$ ions congregate around them (Fig. 3II). The $\mathrm{Cl}^{-}$ions surround $\mathrm{Zn}^{2+}$ ions; therefore, $\mathrm{Zn}^{2+}$ ions 
Fig. 3 Schematic illustration of the mechanism of the formation of holes
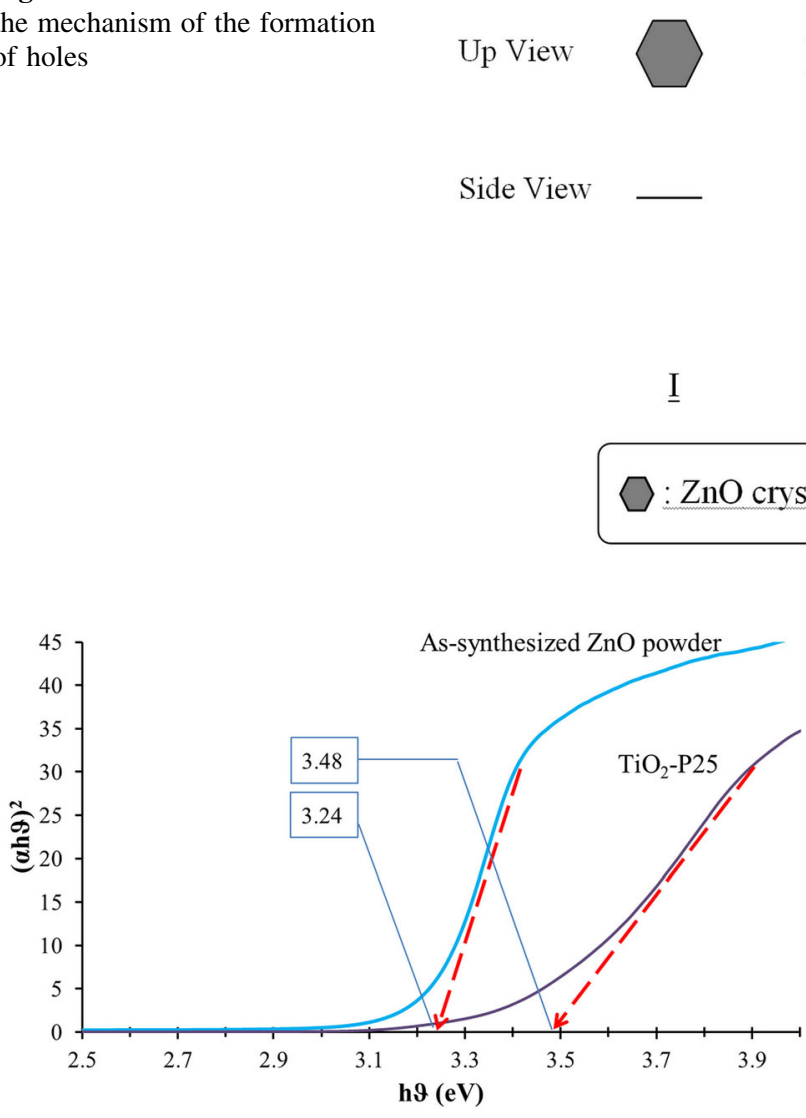

Fig. 4 Tauc results for $\mathrm{ZnO}$ powder

congregate on the edges and addition of the $\mathrm{Zn}^{2+}$ ions onto the facet become restricted (Fig. 3III). The conversion of intermediate product to the oxide form needs sufficient time and energy. In this period, $\mathrm{Cl}^{-}$ions, which are accumulated close to the center of the crystallite, would probably participate in reaction to $\mathrm{Zn}^{2+}$ ions and remove them from the gathering place. This can led to form a hole through a particle (Fig. 3IV). This irregular feature could be considered the reason of the changes in the XRD results, which was previously explained (see Table 1).

As $\mathrm{ZnO}$ powder is known as a photocatalyst, the optical behavior of the as-synthesized powder should be studied.

Figure 4 represents the optical characteristics of the $\mathrm{ZnO}$ nanoflakes and $\mathrm{TiO}_{2}-\mathrm{P} 25$ powder, providing $\mathrm{Eg}$ of nanoflakes and P25 as 3.24 and $3.48 \mathrm{eV}$, respectively. The $E_{\mathrm{g}}$ value of $\mathrm{ZnO}$ powder has been reported in the range of 3.26-3.30 eV [23-25]. This approved that the mentioned morphology cannot essentially affect $E_{\mathrm{g}}$.

Figure 5 shows the kinetics of the photocatalytic degradation of methylene blue suspension containing the as-synthesized $\mathrm{ZnO}$ and $\mathrm{TiO}_{2}-\mathrm{P} 25$ powders. By accordance with the $\ln \left(C_{0} / C\right)$ versus irradiation time, the firstorder kinetic model is valid for both samples, but the

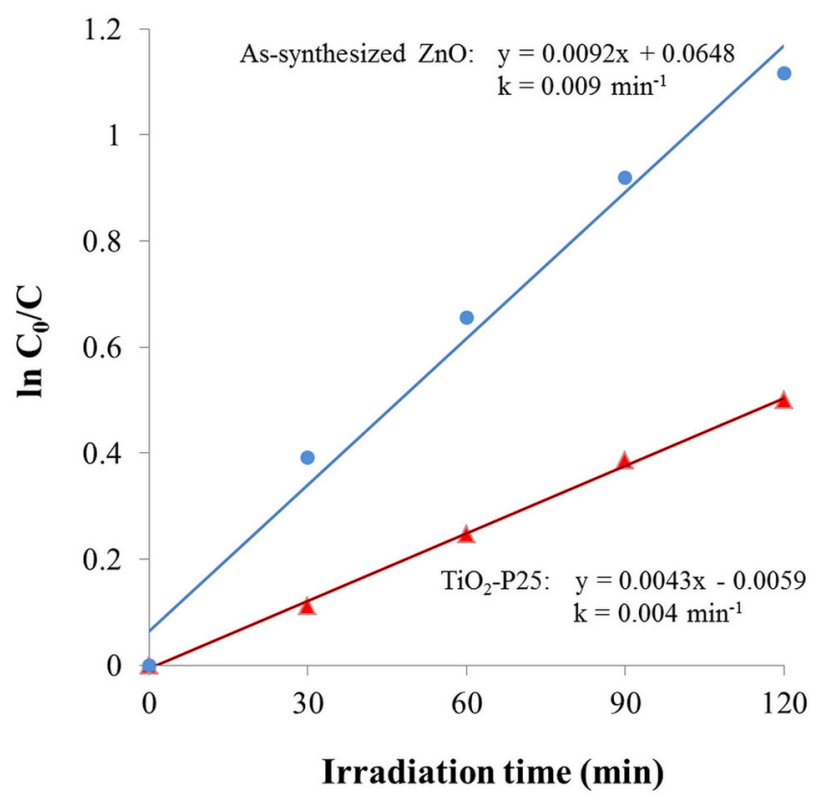

Fig. 5 Kinetics model of the photodegradation of dye solution containing as-synthesized $\mathrm{ZnO}$ powder (filled circles), and $\mathrm{TiO}_{2}-\mathrm{P} 25$ powder (filled triangle)

lines slope show higher photoactivity of the as-synthesized powder in comparison with $\mathrm{TiO}_{2}-\mathrm{P} 25$ nanoparticles. In other words, $k_{\mathrm{ZnO}}\left(0.009 \mathrm{~min}^{-1}\right)$ is more than $k_{\mathrm{P} 25}$ $\left(0.004 \mathrm{~min}^{-1}\right)$. Despite the smaller particle size of P25 and relatively similar band gap energy, as-synthesized $\mathrm{ZnO}$ powder indicates lower photoactivity. This characteristic is correlated to the higher specific surface area, larger pore volume, and higher degree of crystallinity [18]. The observed phenomenon can be referred to the higher surface area and lower $E_{\mathrm{g}}$ value of the as-synthesized powder. $k_{\mathrm{ZnO}}$ is more than two times greater than $k_{\mathrm{P} 25}$, whereas $\mathrm{ZnO}$ particle size is about $1 \mu \mathrm{m} ; 40$ times greater than that of $\mathrm{TiO}_{2}-\mathrm{P} 25$ (average particle size is about $25 \mathrm{~nm}$ ). It may be related to the existence of the holes on the facet of $\mathrm{ZnO}$ particles. 


\section{Conclusions}

Perforated $\mathrm{ZnO}$ nanoflakes were fabricated using the hydrothermal-assisted sol-gel technique without any template. TEA, water, and $\mathrm{ZnCl}_{2}$ were used as catalyst, solvent, and $\mathrm{Zn}$ precursor, respectively. $\mathrm{Cl}^{-}$ion was responsible for the oriented growth and the hole formation during the nucleation and growth of $\mathrm{ZnO}$ particles. They surrounded the crystallites of $\mathrm{ZnO}$ and prevented the addition of $\mathrm{Zn}^{2+}$ to the surface. On the other hand, they probably participate in reaction to $\mathrm{Zn}^{2+}$ and removed them from the vicinity of the crystallite, providing the condition for a hole formation. The synthesized powder consisted of $\mathrm{ZnO}$ wurtzite phase without any impurity and direct bandgap energy of $3.24 \mathrm{eV}$. The particles with $1 \mu \mathrm{m}$ in diameter and less than $50 \mathrm{~nm}$ in thickness were observed. There were circle holes with $300-500 \mathrm{~nm}$ in diameter on the facet of the as-synthesized particles.

Open Access This article is distributed under the terms of the Creative Commons Attribution 4.0 International License (http://creative commons.org/licenses/by/4.0/), which permits unrestricted use, distribution, and reproduction in any medium, provided you give appropriate credit to the original author(s) and the source, provide a link to the Creative Commons license, and indicate if changes were made.

\section{References}

1. Andreyev, D.S., Arriaga, E.A.: Fabrication of perforated submicron silica shells. Scr. Mater. 57(10), 957-959 (2007)

2. Chen, A., Li, Y., Yu, Y., Li, Y., Xia, K., Wang, Y., Li, S., Zhang, L.: Synthesis of hollow mesoporous carbon spheres via "dissolution-capture" method for effective phenol adsorption. Carbon 103, 157-162 (2016)

3. Zhao, T., Luo, W., Deng, Y., Luo, Y., Xu, P., Liu, Y., Wang, L., Ren, Y., Jiang, W.: Monodisperse mesoporous $\mathrm{TiO}_{2}$ microspheres for dye sensitized solar cells. Nano Energy 26, 16-25 (2016)

4. Liu, J., Hui, A., Ma, J., Chen, Z., Peng, Y.: Fabrication and application of hollow $\mathrm{ZnO}$ nanospheres in antimicrobial caseinbased coatings. Int. J. Appl. Ceram. Technol. (2016). doi:10. 1111/ijac. 12635

5. Gharagozlou, M., Baradaran, Z., Bayati, R.: A green chemical method for synthesis of $\mathrm{ZnO}$ nanoparticles from solid-state decomposition of Schiff-bases derived from amino acid alanine complexes. Ceram. Int. 41(7), 8382-8387 (2015)

6. Gharagozlou, M., Naghibi, S.: Synthesis of $\mathrm{ZnO}$ nanoparticles based on $\mathrm{Zn}$ complex achieved from L-leucine. J. Chin. Chem. Soc. 63(3), 290-297 (2016)

7. Wang, H., Xie, J., Yan, K., Duan, M.: Growth mechanism of different morphologies of $\mathrm{ZnO}$ crystals prepared by hydrothermal method. J. Mater. Sci. Technol. 27(2), 153-158 (2011)

8. Xu, L., Hu, Y.-L., Pelligra, C., Chen, C.-H., Jin, L., Huang, H., Sithambaram, S., Aindow, M., Joesten, R., Suib, S.L.: ZnO with different morphologies synthesized by solvothermal methods for enhanced photocatalytic activity. Chem. Mater. 21(13), 2875-2885 (2009)

9. Li, H., Jiao, S., Li, H., Li, L.: Growth and characterization of $\mathrm{ZnO}$ nanoflakes by hydrothermal method: effect of hexamine concentration. J. Mater. Sci. Mater. Electron. 25(6), 2569-2573 (2014)
10. Liu, Y., Dong, J., Hesketh, P.J., Liu, M.: Synthesis and gas sensing properties of $\mathrm{ZnO}$ single crystal flakes. J. Mater. Chem. 15(23), 2316-2320 (2005)

11. Lee, C.-P., Chen, P.-W., Li, C.-T., Huang, Y.-J., Li, S.-R., Chang, L.-Y., Chen, P.-Y., Lin, L.-Y., Vittal, R., Sun, S.-S., Lin, J.-J., Ho, K.-C.: ZnO double layer film with a novel organic sensitizer as an efficient photoelectrode for dye-sensitized solar cells. J. Power Sources 325, 209-219 (2016)

12. Li, S.-Q., Zhou, P.-J., Zhang, W.-S., Chen, S., Peng, H.: Effective photocatalytic decolorization of methylene blue utilizing $\mathrm{ZnO} /$ rectorite nanocomposite under simulated solar irradiation. J. Alloys Compd. 616, 227-234 (2014)

13. Zinc oxide $(\mathrm{ZnO})$ crystal structure, lattice parameters. In: Madelung, O., Rössler, U., Schulz, M. (eds.) II-VI and I-VII Compounds; Semimagnetic Compounds, pp. 1-5. Springer, Heidelberg (1999). Book DOI: 10.1007/b71137, Chapter DOI: 10.1007/10681719_286

14. Nguyen, D.T., Kim, K.-S.: Structural evolution of highly porous/ hollow $\mathrm{ZnO}$ nanoparticles in sonochemical process. Chem. Eng. J. 276, 11-19 (2015)

15. Zhang, J., Wang, S., Wang, Y., Xu, M., Xia, H., Zhang, S., Huang, W., Guo, X., Wu, S.: ZnO hollow spheres: preparation, characterization, and gas sensing properties. Sens. Actuators B Chem. 139(2), 411-417 (2009)

16. Jin, D., Liao, N., Xu, X., Yu, X., Wang, L., Wang, L.: Synthesis of hollow $\mathrm{ZnO}$ microspheres and its novel UV absorption. Mater. Chem. Phys. 123(2-3), 363-366 (2010)

17. Zhu, C., Lu, B., Su, Q., Xie, E., Lan, W.: A simple method for the preparation of hollow $\mathrm{ZnO}$ nanospheres for use as a high performance photocatalyst. Nanoscale 4(10), 3060-3064 (2012)

18. Naghibi, S., Faghihi Sani, M.A., Madaah Hosseini, H.R.: Application of the statistical Taguchi method to optimize $\mathrm{TiO}_{2}$ nanoparticles synthesis by the hydrothermal assisted sol-gel technique. Ceram. Int. 40(3), 4193-4201 (2014)

19. Naghibi, S., Madaah Hosseini, H.R., Faghihi Sani, M.A., Shokrgozar, M.A., Mehrjoo, M.: Mortality response of folate receptor-activated, PEG-functionalized $\mathrm{TiO}_{2}$ nanoparticles for doxorubicin loading with and without ultraviolet irradiation. Ceram. Int. 40(4), 5481-5488 (2014)

20. Vabbina, P.K., Karabiyik, M., Al-Amin, C., Pala, N., Das, S., Choi, W., Saxena, T., Shur, M.: Controlled synthesis of singlecrystalline $\mathrm{ZnO}$ nanoflakes on arbitrary substrates at ambient conditions. Part. Part. Syst. Charact. 31(2), 190-194 (2014)

21. Ghasemzadeh, M.A., Safaei-Ghomi, J., Weaver, G.: Synthesis and characterization of $\mathrm{ZnO}$ nanoparticles: application to one-pot synthesis of benzo[b][1,5]diazepines. Cogent Chem. 1(1), 1095060 (2015)

22. Sugunan, A., Warad, H.C., Boman, M., Dutta, J.: Zinc oxide nanowires in chemical bath on seeded substrates: role of hexamine. J. Sol-Gel Sci. Technol. 39(1), 49-56 (2006)

23. Meyer, B.K.: ZnO band structure, energy gaps. In: Rössler, U. (eds.) New Data and Updates for IV-IV, III-V, II-VI and I-VII Compounds, their Mixed Crystals and Diluted Magnetic Semiconductors, pp. 566-569. Springer, Heidelberg (2011). Book DOI: 10.1007/978-3-642-14148-5, Chapter DOI: 10.1007/978-3642-14148-5_316

24. Deng, Z., Chen, M., Gu, G., Wu, L.: A facile method to fabricate $\mathrm{ZnO}$ hollow spheres and their photocatalytic property. J. Phys. Chem. B 112(1), 16-22 (2008)

25. Özgür, Ü., Alivov, Y.I., Liu, C., Teke, A., Reshchikov, M.A., Doğan, S., Avrutin, V., Cho, S.-J., Morkoç, H.: A comprehensive review of $\mathrm{ZnO}$ materials and devices. J. Appl. Phys. 98(4), 041301 (2005). doi:10.1063/1.1992666 